\title{
Al calor de la masculinidad. Clima, migración y normativas de género en la Costa de Hermosillo, Sonora
}

In the heat of masculinity. Climate, migration and gender regulations in Costa de Hermosillo, Sonora

\author{
José Eduardo Calvario Parra* \\ Rolando Enrique Díaz Caravantes ${ }^{* *}$
}

Resumen: ${ }^{1}$ en este estudio sobre migrantes jornaleros(as) agrícolas en la Costa de Hermosillo, Sonora, se presenta una primera aproximación analítica y descriptiva respecto a la relación entre clima y masculinidad en el noroeste de México. A través de un enfoque metodológico cualitativo, por medio de entrevistas semiestructuradas y observaciones de campo, se explora el vínculo entre las normativas masculinas y las prácticas o discursos relacionados con el cuidado ante el calor natural excesivo. La conclusión es que las condiciones de vulnerabilidad estructural que viven los/as trabajadores/ as agrícolas están acompañadas con ideologías de género, que en situaciones determinadas se vuelven cruciales para tomar la decisión de cuidarse de las temperaturas altas o de no hacerlo.

* Catedrático del Consejo Nacional de Ciencia y Tecnología-El Colegio de Sonora (COLsOn). Avenida Obregón 54, colonia Centro, C. P. 83000, Hermosillo, Sonora, México. Teléfono: (662) 259-5300, extensión 2299. Correo electrónico: jcalvario@colson.edu.mx

** Profesor-investigador del Centro de Estudios en Salud y Sociedad del colson. Avenida Obregón 54, colonia Centro, C. P. 83000, Hermosillo, Sonora, México. Teléfono: (662) 2595300, extensión 2294. Correo electrónico: rdiaz@colson.edu.mx

1 Agradecemos a todas las personas que hicieron posible la realización del trabajo de campo, en especial a los/as jornaleros/as agrícolas migrantes por las entrevistas concedidas, para conocer parte de sus vidas. 
Palabras clave: masculinidad; migración interna; jornaleros agrícolas; riesgos ambientales; clima extremo; Costa de Hermosillo.

Abstract: in this study on migrant agricultural workers in the Costa de Hermosillo, Sonora, we present a first analytical and descriptive approximation of the interaction between climate and masculinity in northwestern Mexico. Through a qualitative methodological approach, which includes semistructured interviews and field observations in the region studied, we explore the link between male regulations and practices and discourses related with care under conditions of excessive natural heat. It is concluded that the conditions of structural vulnerability in which agricultural workers live are accompanied with gender ideologies that under certain conditions become crucial when deciding to be careful or not with high temperatures.

Key words: masculinity; internal migration; agricultural laborers; environmental hazards; extreme weather; Costa de Hermosillo.

\section{Introducción}

En América Latina, el interés por el estudio de las masculinidades desde las ciencias sociales, con énfasis en el género, tiene poco tiempo (Viveros 1997); así lo constata la producción académica de trabajos colectivos como los de Careaga y Cruz (2006); Amuchástegui y Szasz (2007); Hernández et al. (2011) y Ramírez y Cervantes (2013), ${ }^{2}$ que han aumentado notablemente en México. Dichos grupos de trabajo han abordado temáticas de políticas públicas y también las prácticas sexuales no seguras. Sin embargo, no se ha tratado la interacción entre las relaciones de género, la construcción social de la masculinidad y el clima. ${ }^{3}$

2 El trabajo de Guillermo Núñez (2013) es imprescindible para entender la lógica de cambio en las relaciones de género en Sonora.

3 En México existen trabajos que abordan la cuestión ambiental desde el género, pero en la tónica del llamado ecofeminismo (Saldaña 2015), o en los que el foco principal son las 
En este trabajo se presenta un primer acercamiento a la relación entre las normativas de género vinculadas con definiciones sociales sobre el ser varón, y la percepción del riesgo por calor en contextos migratorios en el noroeste de México. Existe un conjunto de factores que dificultan las trayectorias migratorias de las personas que por distintos motivos salen de sus lugares de origen hacia algún sitio de Sonora. Uno de ellos es el clima, que se ha explorado poco desde las ciencias sociales, y menos aún en relación con las ideas culturales que están tras las prácticas frente al peligro que representan las temperaturas altas (Ulloa 2011).

En cualquier modalidad migratoria, el efecto climático que produce la temperatura elevada en la salud no es un riesgo futuro sino un daño actual, pues la climatología de algunas regiones de México representa en sí misma un problema, como en Sonora. De las 393 personas fallecidas en territorio nacional por calor natural excesivo de 2002 a 2010, más de una tercera parte eran trabajadoras del sector primario, y en su gran mayoría murieron en Sonora (Díaz et al. 2014).

Este artículo es parte de una investigación más amplia, que exploró las percepciones del riesgo climático de migrantes internacionales y jornaleros/as agrícolas en tránsito por Sonora. En cuanto a la migración interna, se realizó trabajo de campo de abril a julio de 2014; se llevaron a cabo 20 entrevistas semiestructuradas en el poblado Miguel Alemán (PMA), Sonora. El análisis que se presenta, deriva de las entrevistas y las observaciones de campo en esta localidad y periodo.

Durante el trabajo de campo, y en las primeras revisiones del material empírico se advirtieron diferencias respecto a la percepción entre los varones y las mujeres sobre el peligro que representan las altas temperaturas. El común denominador fue la necesidad improrrogable de hacerle frente a las amenazas socioambientales. En este escenario, se creyó conveniente abordar los discursos y prácticas de los/as jor-

mujeres (Tuñón 2003; Cedillo y Cano 2012). En Sonora no hay estudios sobre la relación clima, migración y masculinidad, aunque se ha señalado el vínculo entre los dos últimos factores (Calvario y Salazar 2012). Se revisaron las investigaciones en México sobre desastres naturales y sociedad (que incluyen la dimensión climática y el género); hasta octubre de 2015 se había sistematizado un promedio de 300 trabajos; pero no hay registro de estudios que traten los ejes de masculinidad, salud y clima, o de migración, masculinidad y clima. 
naleros/as, en especial lo que hacen o dicen que hacen los varones en torno al clima. El estudio es exploratorio, ya que no existían investigaciones sobre los temas mencionados desde las ciencias sociales; ${ }^{4}$ puede ser el inicio de otros en los cuales se profundicen, aclaren y amplíen algunos de los elementos que se expondrán a continuación, como resultados preliminares.

El primer apartado contiene un panorama breve de los antecedentes contextuales en cuanto a la migración interna de jornaleros/as agrícolas, la salud y el clima en la región. En el segundo se presenta el problema de investigación y el núcleo central de los interrogantes. En el tercero se describe el perfil de los/as entrevistados/as y las técnicas de recopilación de información. En el cuarto se discute y expone el marco teórico que soporta la recopilación y análisis del material empírico. En el quinto y el sexto se describe el lugar de estudio y se analizan algunos de los hallazgos en torno a los ejes: normativas masculinas, riesgos y clima. Al final se incluyen conclusiones preliminares respecto a la interseccionalidad de los ejes de vulnerabilidad social que viven los/as jornaleros/as migrantes. Con ello se sostiene que existe un juego de normas y significados que exacerban las vulnerabilidades ante el clima o, en caso contrario, ayudan a prevenir posibles daños.

\section{El contexto: migración interna, clima y salud}

Con base en la Encuesta nacional sobre jornaleros agrícolas (Secretaría de Desarrollo Social, SEDESOL 2011), el informe del Centro de Derechos Humanos de la Montaña Tlachinollan, de Guerrero, señala que 405712 familias mexicanas salen de los lugares de origen y regresan a ellos $(2012,13)$.También, que 26 por ciento de los mexicanos son migrantes y, de ellos, nueve de cada diez son internos. Y estima que, según mediciones anteriores a 2009, había 3.5 millones de varones y mujeres migrantes, la mayoría de origen indígena, que se desplazaban dentro del país o que lo habían hecho. Según la SEDESOL (2011), en

4 En México hay trabajos sobre la masculinidad y salud (De Keizjer 1998; Rivas 2005), la masculinidad y la migración (Rosas 2008), pero no respecto al cruce analítico entre masculinidad y clima. 
2009 en México existían poco más de 2 millones de jornaleros/as, que vendían su fuerza de trabajo en el ámbito de la agricultura.

Según fuentes oficiales, entre 2002 y 2003, en las regiones dedicadas a la agricultura intensiva de exportación en Sinaloa, Sonora y Baja California, los contingentes de asalariados rebasaban los 300 mil (Carton de Grammont 2007). En Sonora llegan a residir hasta 80 mil, según el Programa Nacional de Jornaleros Agrícolas (Ortega et al. 2007). Si a esta población se le agrega la que ya está asentada, sumarían 100 mil. La presencia de los/as jornaleros/as ha sido parte y respuesta del proceso de la economía mundial, en el contexto de las cadenas productivas agroalimentarias globales. El requerimiento masivo de mano de obra barata ha sido consustancial.

Existen investigaciones que han documentado el flujo migratorio cuyo actor principal ha sido el/la jornalero/a agrícola. La relación entre migración y trabajo agrícola es unívoca, sobre todo para Sonora y su región central. Del año 2000 a 2003, se documentaron las condiciones de vida de dichos/as trabajadores/as provenientes de Oaxaca, Puebla, Veracruz, Guerrero, Chiapas, Michoacán, Nayarit, Zacatecas, Morelos, México y Sinaloa en varios campos agrícolas del estado, en función de la modalidad migratoria y el tipo de unidad de producción para la cual fueron contratados/as. Muchos de estos campos se catalogaron como precarios, por el hacinamiento, insalubridad del medio ambiente (defecación al aire libre, ingesta de agua contaminada) e infraestructura de atención (ausencia de trabajadoras/es sociales y enfermeros/as) (Sariego y Castañeda 2007, 122).

En el noroeste de México, donde se ubica Sonora, se registró un aumento mayor de la temperatura en casi todo el siglo xx (Conde y Gay 2008, 47). En cuanto a la relación entre la salud humana y un posible cambio climático, Moreno señala que "se ha reportado una relación positiva y significativa entre la temperatura y la mortalidad por golpe de calor en los estados de Sonora y Baja California" $(2010,24)$.

En Sonora hay registro de las temperaturas desde 1925, y si se considera hasta 2011 , la máxima extrema para julio fue de $51^{\circ} \mathrm{C}$ en promedio; en contraste la mínima extrema para enero fue de $-7.5^{\circ}$ C (Comisión Nacional del Agua, ConAGUA 2014). Una investigación nacional documentó que de 2002 a 2010 hubo 393 fallecimientos por calor natural excesivo; 150 murieron en Sonora: 90 por ciento de 
varones y 10 de mujeres, y 42.7 de estas personas trabajaba en actividades del sector primario.

Del año 2000 a 2002, en la Costa de Hermosillo (en lo sucesivo, La Costa) hubo nueve muertes por exposición a fuerzas de la naturaleza, incluye calor y frío (Calvario 2003). Se supone que los/as jornaleros/as son las personas más afectadas, puesto que constituyen la principal fuerza laboral y, sobre todo, porque están expuestas a las inclemencias del ambiente biofísico. En este contexto, el clima extremo como una amenaza para la salud de los/as migrantes jornaleros/ as se ha estudiado muy poco, a pesar de que en varios trabajos se reconoce tangencialmente. Según un informe de investigación en tres campos agrícolas de la zona Pesqueira-Zamora y Guaymas, casi 60 por ciento de los/las entrevistados/as se enfermaron, y 75 no tenía acceso a seguridad social (Ortega et al. 2008, 16-17). En 52 campos de la entidad se documentó prevalencia elevada de parasitosis; entre las jornaleras con enfermedades crónicas no trasmisibles, había una relación conforme aumenta su tiempo de residencia en la región norte del país (Ortega y Castañeda 2007, 154).

\section{El problema: la masculinidad y la percepción del riesgo}

Aquí se explora la percepción del/la jornalero/a agrícola sobre el riesgo ante el clima. Este vínculo posible, y por tanto hipotético, de ninguna manera es mecánico y mucho menos monolítico, es decir, existe la posibilidad de que ciertos varones, en determinadas circunstancias, perciban el riesgo de tal forma que desplieguen prácticas preventivas, así como también mujeres "temerarias" que no lo hagan. Se sostiene que en ciertas situaciones el género, junto con las condiciones estructurales, orienta las prácticas frente al calor extremo. En términos discursivos, la experiencia de la enfermedad y las molestias por el calor fue más acentuado en las mujeres, pues se quejaban más. También hubo varones que enfermaban gravemente (aunque el clima no fue la causa directa) y a pesar de ello laboraban. Hay que tener precaución ante los relatos de los/as informantes en el sentido de ubicarlos en el contexto social y en el biográfico. 
Aquí se considera que opera un sistema de ubicación social en el cual no sólo se clasifica, distingue, separa o jerarquiza a los seres humanos en dos categorías fundamentales: varones y mujeres, sino que además reproducen valores, normas e ideas que acentúan dicho proceso. Por tanto, se cree que existe una carga cultural que influye, aunque no de forma determinante, en los discursos y las prácticas sociales frente a los peligros.

Las temperaturas extremas son amenazas para la salud de los/as jornaleros/as de la región, y las respuestas de los individuos también estarán en función de los efectos y, por tanto, de la gravedad que les provoque el calor. ${ }^{5}$ Es posible que se relativice el problema según la experiencia previa (incluso migratoria), la intensidad del calor ${ }^{6}$ y las condiciones biológicas y sociales de los individuos que se exponen a las temperaturas altas.

Uno de los indicadores que refleja los efectos de las temperaturas elevadas es la mortalidad por esta causa. En un recuento por municipio, de 2002 a 2010, Hermosillo ocupó el segundo lugar con 48 defunciones, sólo superado por Mexicali con 70 (Díaz et al. 2014). Si se consideran los sitios donde está más acentuado el fenómeno, La Costa ocupó el segundo lugar con 13 fallecimientos. Este dato es elocuente, porque la actividad principal en esta región es la agricultura y, por ende, los/as trabajadores/as que se emplean en esas tareas están expuestos a más de $40^{\circ} \mathrm{C}$. Pero además, si se parte de que tanto a escala nacional como en esta zona hubo más muertes masculinas que femeninas, se puede presuponer que los varones experimentan un costo elevado para su salud.

5 En la literatura biomédica se identifica al golpe de calor como síndrome inducido por el calor natural cuando la temperatura del cuerpo rebasa los $42^{\circ} \mathrm{C}$ y, según Piñeiro et al. (2004), se produce un daño por toxicidad celular directa debido al cese de la actividad mitocondrial, también hay una inestabilidad en la membrana celular y alteraciones en los enlaces químicos mitocondriales. Los efectos en el cuerpo son variados: a) en el sistema nervioso central (alteraciones sutiles del comportamiento, convulsiones, delirio, incluso coma); b) manifestaciones musculares y cardiacas como hipotensión, taquicardia e hiperventilación, debido al esfuerzo del corazón durante el proceso de vasodilatación; c) dificultades para respirar; d) daños en el hígado y e) hipoglucemia.

6 En los estudios geofísicos se ha señalado que los intervalos para considerar ondas de calor variarán según las condiciones de los lugares, por ejemplo para el noroeste de México, en especial en los municipios de Mexicali y Hermosillo, una onda de calor es cuando hay dos o más días consecutivos con más de $40.6^{\circ} \mathrm{C}$ (temperatura aparente-índice de calor que incluye el efecto combinado de temperatura alta y humedad) (Jáuregui et al. 2008, 19). 
Las preguntas planteadas son: ¿cómo es que las normativas de género, en especial las masculinas, influyen en la percepción del riesgo ante altas temperaturas en los jornaleros agrícolas migratorios? ¿De qué manera interactúan el proceso migratorio y la reconfiguración de las relaciones de género con marcadores climáticos, como las altas temperaturas? Dichos interrogantes guían los resultados, pero sólo representan un primer acercamiento, y de ningún modo se pretende darles respuestas tajantes. La hipótesis de trabajo es que los varones y mujeres enfrentan un conjunto de adversidades durante el proceso migratorio, desde su lugar de origen hasta el de destino (La Costa), pero en ambos géneros existe un diferencial en la manera de percibir y actuar ante el riesgo por altas temperaturas, en específico sobre la idea tradicional de la fortaleza masculina. Se considera a la masculinidad como una categoría de análisis que alude al proceso de construcción de un imaginario social, que mantiene su fuerza debido a la legitimación de lo que es propio de "hombres" y lo que no lo es.

En un estudio sobre jornaleros asentados con antecedentes migratorios en la región agrícola de Zamora, Michoacán, José Luis Seefoó llama la atención respecto a la idea cultural de la culpa como control social en relación con los riesgos laborales, como los de los plaguicidas $(2005,270)$. Aquí se coincide con el autor, en el sentido de que la idea de las calamidades o los destinos irreversibles hacen mella en las creencias frente al riesgo. No obstante, las dinámicas de género, entendidas como relaciones desiguales de poder entre varones y mujeres, pueden ayudar a ampliar la mirada respecto a las formas de entender y actuar frente al riesgo. La atribución causal de la fatalidad puede tener orígenes distintos, desde el religioso hasta la idea de un destino azaroso convertido en mala suerte, pero los mecanismos que convierten el origen del problema en culpa son genéricamente diferenciales. Como dice Seefoo, los/as jornaleros/as agrícolas sortean todo tipo de adversidades, a ello se le suma que en las trayectorias migratorias existen riesgos que pueden menguar la salud e incluso provocar la muerte. Baste recordar que la migración internacional implica, para algunas rutas, desafíos como atravesar el desierto de Altar, enfrentar las bandas delincuenciales y las extorsiones policiacas (Comisión Interamericana de Derechos Humanos, CIDH 2013). Tanto los/as migrantes internos/as como internacionales comparten 
un cuadro de riesgos y amenazas permanentes. Se considera que el género es una lente plausible para aumentar el acercamiento analítico en torno al riesgo y el peligro referido a las temperaturas altas.

\section{Aspectos metodológicos}

El enfoque es cualitativo, ya que se privilegian las narrativas de los agentes y, sobre todo, el sentido que le otorgan a sus experiencias. Se optó por este acercamiento metodológico porque se pretendía explorar los significados sobre los riesgos ante temperaturas altas en los migrantes que residen en Sonora o transitan por el estado. Como técnica principal se eligió la entrevista cualitativa estructurada, su duración promedio fue de una hora; se elaboró una guía de preguntas en dos partes. En la primera se solicitaron datos sociodemográficos generales (edad, condición civil, lugar de origen, composición familiar, formas de desplazamiento) y las preguntas fueron cerradas; en la segunda se pidió información sobre el motivo migratorio, el clima, la salud, las prácticas preventivas frente al calor, la identificación de peligros, la experiencia migratoria previa y las redes de apoyo. Se grabaron 19 entrevistas en el PMA, ubicado en el centro occidente de Sonora, región conocida como La Costa de Hermosillo, a jornaleros/as de Guerrero, Chiapas, Veracruz, Tabasco, Puebla y Oaxaca y, en menor medida, de Sinaloa, Nayarit y Chihuahua.

El objetivo del trabajo de campo fue registrar y contrastar las prácticas preventivas ante las altas temperaturas; para lograrlo se realizaron tres inmersiones en mayo, junio y julio. En verano, el termómetro en la región oscila entre 40 y $47^{\circ} \mathrm{C}$ a la sombra, de ahí la importancia de hacer las entrevistas en esta estación. Según registros de la CONAGUA (2014), la temperatura máxima en el municipio de Hermosillo ha alcanzado los $51^{\circ} \mathrm{C}$. Aunque algunos/as entrevistados/as relataron que en sus lugares de origen también sufrían incomodidades por este motivo, todos/as coincidieron en señalar que el clima de la región les provocaba molestias mayores.

Todos los encuentros se llevaron a cabo en los domicilios de las personas; la mayoría vivía temporalmente en lugares conocidos como "cuarterías", pues el/la propietario/a ofrece el servicio de renta de 


\section{Figura 1}

\section{Información general de los/as entrevistados/as en el PMA, mayo-julio 2014}

\begin{tabular}{|c|c|c|c|c|c|c|c|c|}
\hline & Seudónimo & Edad & Grado escolar & $\begin{array}{c}\text { Situación } \\
\text { civil }\end{array}$ & Procedencia & $\begin{array}{c}\text { Fecha de } \\
\text { salida }\end{array}$ & Etnia & $\begin{array}{c}\text { Primera } \\
\text { vez }\end{array}$ \\
\hline 1 & Herminia & 29 & Secundaria & Viudez & Chiapas & $\begin{array}{c}\text { Marzo } \\
2014\end{array}$ & Mestiza & Sí \\
\hline 2 & Sócrates & 34 & 3ro de primaria & Soltero & $\begin{array}{l}\text { EE UU/ } \\
\text { Oaxaca }\end{array}$ & 2001 & Amuzgo & No \\
\hline 3 & Carla/os* & 35 & 4to de primaria & Soltera/o & $\begin{array}{l}\text { Tabasco/ } \\
\text { Ensenada }\end{array}$ & $\begin{array}{c}2001 / \\
\text { mayo-2014 }\end{array}$ & Mestizo & No \\
\hline 4 & Carlos & 23 & Secundaria & $\begin{array}{l}\text { Unión } \\
\text { libre }\end{array}$ & Chiapas & $\begin{array}{c}\text { Noviembre } \\
2013\end{array}$ & Tzeltal & No \\
\hline 5 & Aracely & 21 & Preparatoria & $\begin{array}{l}\text { Unión } \\
\text { libre }\end{array}$ & Chiapas & $\begin{array}{l}\text { Abril } \\
2014\end{array}$ & Tzeltal & Sí \\
\hline 6 & Miguel & 27 & 5to de primaria & Soltero & Chihuahua & 2003 & Tarahumara & $\mathrm{No}$ \\
\hline 7 & Rosa & 38 & Secundaria & $\begin{array}{l}\text { Unión } \\
\text { libre }\end{array}$ & Veracruz & $\begin{array}{l}\text { Abril } \\
2013\end{array}$ & Mestiza & Sí \\
\hline 8 & Petra & 36 & $\begin{array}{c}\text { 3ro de } \\
\text { primaria }\end{array}$ & $\begin{array}{l}\text { Unión } \\
\text { libre }\end{array}$ & Puebla & $\begin{array}{l}\text { Mayo } \\
2014\end{array}$ & Mestiza & No \\
\hline 9 & Rosario & 35 & $\begin{array}{c}\text { Primer año de } \\
\text { preparatoria }\end{array}$ & Casada & Chiapas & Abril 2014 & Tzeltal & Sí \\
\hline 10 & Francisco & 19 & 3ro de primaria & Soltero & Veracruz & $\begin{array}{l}\text { Junio } \\
2014\end{array}$ & Mestizo & Sí \\
\hline 11 & Erasmo & 27 & Secundaria & Separado & Veracruz & $\begin{array}{l}\text { Junio } \\
2014\end{array}$ & Náhuatl & Sí \\
\hline 12 & Rubén & 37 & 3ro de primaria & $\begin{array}{l}\text { Unión } \\
\text { libre }\end{array}$ & Veracruz & $\begin{array}{l}\text { Junio } \\
2014\end{array}$ & Mixteco & Sí \\
\hline 13 & Ismael & 40 & 4to de primaria & Divorciado & $\begin{array}{l}\text { EE UU/ } \\
\text { Jalisco }\end{array}$ & $\begin{array}{c}\text { Octubre } \\
2013\end{array}$ & Mestizo & No \\
\hline 14 & Osvan & 40 & 4to de primaria & $\begin{array}{l}\text { Unión } \\
\text { libre }\end{array}$ & Chiapas & $\begin{array}{c}\text { Octubre } \\
2013\end{array}$ & Mestizo & No \\
\hline 15 & Raúl & 24 & 5to de primaria & Separado & Guerrero & $\begin{array}{c}\text { Diciembre } \\
2014\end{array}$ & Mestizo & No \\
\hline 16 & María & 19 & 6to de primaria & Separada & Sinaloa & -------- & Mestiza & Sí \\
\hline 17 & Pancracio & 33 & $\begin{array}{l}\text { 2do año de } \\
\text { preparatoria }\end{array}$ & $\begin{array}{l}\text { Unión } \\
\text { libre }\end{array}$ & Puebla & $\begin{array}{c}\text { Febrero } \\
2014\end{array}$ & Mestizo & Sí \\
\hline 18 & Lencho & 58 & 5to de primaria & $\begin{array}{l}\text { Unión } \\
\text { libre }\end{array}$ & Nayarit & $\begin{array}{c}\text { Diciembre } \\
2014\end{array}$ & Mestizo & No \\
\hline 19 & Javier & 29 & --------- & Casado & Guerrero & Abril 2014 & Mestizo & No \\
\hline
\end{tabular}

* A esta persona, se le puede categorizar biológicamente como macho humano, dicha nominación cultural se traduce con otra: "hombre"; no obstante, esta persona asume una identidad de género distinta, cercana a la identidad homosexual, la dueña de la cuartería le habla y trata como mujer, en femenino.

Fuente: elaboración propia. 
varios cuartos. En general, las condiciones de vivienda son deficientes por la antigüedad de la estructura habitacional o por el material empleado en la construcción (paredes de adobe, techos de lámina, piso de tierra). Una gran parte de los/as entrevistados/as no contaban con aparatos de aire artificial para paliar las temperaturas altas, cuando mucho, algunos/as tenían un ventilador eléctrico. En los campos agrícolas tampoco cuentan con aparatos de refrigeración o alguna otra forma para enfrentar el calor extremo. Cabe recordar que los/as informantes tenían su residencia en el PMA aunque algunos/as vivían en algún campo agrícola de la región.

\section{Marco analítico}

Las prácticas sociales que despliegan los agentes tienen una lógica que se construye colectivamente. La construcción de la idea del riesgo o peligro respecto al clima extremo, y las prácticas vinculadas a ésta, se basan en una lógica social que refleja la interacción constante entre factores socioambientales. El riesgo y el peligro son dos conceptos distintos, pero vinculados entre sí, ambos aluden a procesos de construcción social sobre las posibilidades de ocurrencia de un evento negativo, que puede ocasionar daño, y respecto a los factores detonantes de éste. El género es uno de los elementos que ayuda a entender dichas prácticas, pero también las representaciones sobre ellas; se considera como una categoría analítica, en tanto heurística positiva que permite plantear interrogantes, unir piezas de rompecabezas o zonas de indagación nuevas (Hawkesworth 1996, 11).

En términos teóricos, el género se refiere al sistema de ubicación, marcación, distinción y clasificación, gracias al cual se fabrican las diferencias entre machos y hembras de la especie humana. La división ocurre mediante un proceso simbólico, que reafirma las distancias entre las categorías sociales cuyo elemento principal es el cuerpo (Lamas 1996; Scott 1996). El funcionamiento de este sistema se puede explicar a través del poder, en particular de las relaciones sociales de dominación. El género representa un eje de diferenciación social, y también contribuye a la reproducción de modelos y estructuras normativas, que imponen formas de actuar en varones y mujeres. Se sos- 
tiene que desplegar prácticas preventivas o contrarias a éstas, frente al calor, tiene un trasfondo normativo de género, que puede inclinar o no la balanza hacia la prevención de riesgos y peligros.

La masculinidad es parte del sistema de género, por ello se exploran las vivencias de los varones expresadas en los relatos, es decir, se reconstruyen sus experiencias como "hombres" que enfrentan un mundo de desafíos constantes: la salud ante las altas temperaturas. A continuación se aborda la masculinidad y los daños a la salud, con el objetivo de mostrar cómo están vinculados.

Aquí, la masculinidad representa un conjunto de posiciones sociales en las cuales los varones se ubican para llevar a cabo prácticas y discursos que ratifican, definen, disputan o negocian lo que es "ser hombre" (Calvario 2014). El trabajo es un eje importante de ubicación social el cual contribuye a la construcción de las identidades masculinas (Fuller 1998). La migración se convierte en una experiencia que llega a incidir en la validación del individuo como hombre, por los peligros que involucra (Rosas 2008). Dichas posiciones están vinculadas con símbolos y significados que promueven definiciones determinadas sobre lo masculino, es decir, lo que representa considerarse "hombre". Se trata de un concepto que involucra patrones estructurales que hacen posible la reproducción de la matriz de la dominación masculina.

En décadas pasadas, la literatura estadounidense se interesó en la manera en que los roles sociales y algunas enfermedades y causas de muerte eran y siguen siendo diferenciales; se constató que el rol masculino o femenino repercutía en la salud (Verbrugge 1985; Waldron 1995). En México, Benno De Keijzer abonó a dicha hipótesis, en especial con la incorporación de los desarrollos sugestivos de estudiosos de la masculinidad como Michael Kaufman y su tríada de la violencia, y de Luis Bonino con la idea del factor de riesgo adjudicado al mismo varón (citados en De Keijzer 1998). De esta manera se ha fraguado la idea de que existe un modelo de masculinidad occidental, que favorece el desencadenamiento de algunos daños a la salud. La experiencia en investigaciones anteriores ha permitido incursionar en la construcción social del ser "hombre" y su vínculo con la salud; se ha puesto a prueba la hipótesis sobre la relación entre lo que se ha llamado masculinidad occidental y los daños a la salud (Calvario 2014; 2003). 
En la región de estudio existe un modelo masculino tradicional, caracterizado por un eje rector normativo: la proveeduría familiar fincada en la fortaleza de los "hombres" (Calvario 2014). A este imperativo le acompaña la idea transcultural de la protección masculina de la familia. Se promueve que los varones deben ser los únicos proveedores, y estar en condiciones para enfrentar desafíos sin vacilar y con determinación, incluso a costa de su propia salud, pero en aras de la responsabilidad familiar; el cuidado está en función de quienes se pretende proteger. Hay otro modelo que se expresa en la región de estudio, el cual reivindica la idea de la valentía pero la responsabilidad familiar es desplazada por el descuido y la irresponsabilidad. Dichos modelos masculinos de ninguna forma son monolíticos, sino que en ciertas circunstancias son flexibles, movibles y se imbrican entre sí. Más allá de considerar las definiciones sobre los conceptos mencionados como "buenas" o "malas”, aquí se usan de manera heurística, es decir, como guías de interpretación y análisis de los datos.

\section{El lugar destino: La Costa y el poblado Miguel Alemán}

La Costa se encuentra dentro de los circuitos productivos de exportación agrícola dirigidos a satisfacer la demanda de frutas y legumbres del mercado estadounidense, canadiense, asiático y europeo. El centro occidente agrícola de Sonora le debe su dinámica económica y generación de empleos a los procesos económicos del último cuarto del siglo pasado. La apertura comercial de México hacia el exterior, sobre todo a Estados Unidos, facilitó el aumento de los jornales generados en La Costa y la reproducción del capital regional. Con este proceso se expresaron rasgos inequívocos de lo que se ha llamado flexibilidad primitiva, la cual alude a una "arbitrariedad empresarial" (poca regulación y control del proceso productivo por parte del Estado, la exclusión de sindicatos de la empresa) con formas antiguas de organización del trabajo (De la Garza, citado en Lara 1992, 33).

Un rasgo característico de esta región, vinculada con la dinámica económica, es la experiencia cíclica de sus habitantes respecto a la inestabilidad y la incertidumbre en el empleo. En julio, agosto y parte de septiembre los jornaleros agrícolas se ven deambulando por las 
calles del poblado principal de la zona buscando formas de sobrevivencia, porque hay poco trabajo o ninguno. Aunado al desempleo y, por si fuera poco, desde el final de la cosecha de vid hasta septiembre las temperaturas tienen sus picos máximos. ${ }^{7}$

En los campos agrícolas se recibe a cientos de trabajadores/as que arriban a La Costa con la esperanza de obtener un ingreso. En la estancia breve o larga, según sea el caso, las condiciones objetivas de vida son difíciles. No se les proporciona equipo electrodoméstico para enfrentar el clima extremo; hay algunos que adquieren un ventilador. El PMA alberga a cientos de familias que viven en unidades habitacionales, que incluyen las cuarterías. Aquí se estudió a las personas que residen temporalmente en dichos conjuntos, que son construcciones endebles en esta localidad, que se conformó gracias a los flujos migratorios de las décadas de 1960 y 1970. Este lugar se usaba como campamento y dormitorio de miles de pizcadores de algodón en los años cincuenta. Hoy tiene alrededor de 30 mil habitantes, y está supeditado política y administrativamente al municipio de Hermosillo (Calvario 2014).

La llegada a La Costa y el clima

La migración y la salud de los/las jornaleros/as están en interacción permanente, sobre todo respecto a las condiciones de traslado, residencia y trabajo, junto a sus vivencias en la comunidad. ${ }^{8}$ Las temperaturas que superan los $40^{\circ} \mathrm{C}$ son escenarios propicios que provocan molestias para la salud. La mayoría de los jornaleros agrícolas migratorios que arriban a La Costa u otras zonas áridas de Sonora (Caborca, Pesqueira y Empalme), sabían sobre el clima extremo antes de salir

7 La contratación de mano de obra externa y el desplazamiento de cientos de jornaleros hacia otras regiones se ha debido a las necesidades del mercado de trabajo agrícola. La conversión del patrón de cultivo llevó a muchos productores a sustituir la siembra tradicional (trigo y algodón) por la que demandan los mercados europeo y estadounidense, con ello aumentó la masificación de la fuerza laboral, pero con un costo, por ejemplo la vid sólo se reproduce en un ciclo por año. Esto ha generado periodos de desempleo agudo, sobre todo en la localidad principal de la zona.

8 Algunos contingentes de los estados vecinos del sur, que arriban a tierras costeñas, regresan a sus pueblos cuando termina el contrato verbal con el intermediario llamado "contratista"; otros, los menos, se quedan viviendo en el campo agrícola, y algunos más se desplazan hacia zonas vecinas o se trasladan hacia Estados Unidos. 
de los lugares de origen. Cuando alguien sale por primera vez, la información se la proporciona algún familiar o las redes sociales que se organizan con la finalidad de desplazarse a otras localidades. Poco más de la mitad de los/as entrevistados/as ya tenían experiencia en tierras sonorenses. En su mayoría eran mujeres las que arribaban por primera vez a Sonora; fueron las que más se quejaron de las condiciones climáticas. Durante un encuentro no grabado se registró la situación siguiente:

Al cruzar un pequeño pasillo, frente a los lavaderos, estaba abierto un cuarto y dentro de éste una mujer acostada a ras de piso, le acompañaban un par de niños. Se trataba de C., originaria de Chiapas, del municipio de Tuxtla Gutiérrez, nacida en la localidad 16 de Septiembre (PMA, mayo de 2014).

La mujer tenía la blusa levantada hasta la zona del ombligo, y en el cuarto había un ventilador para enfriar un poco el aire que, alrededor de las 11 de la mañana, ya era muy caliente. Al verla postrada y explicarle el propósito de la entrevista, y puesto que durante los primeros instantes no decía nada, se le preguntó si estaba enferma y respondió que no, segundos después se levantó con una ligera sonrisa. No había muebles en la habitación, como una silla, una mesa, un televisor o una cama. Del techo colgaba un cable eléctrico cubierto de moscas. Una niña de alrededor de cuatro años jugaba, y el hijo menor, de un año, de vez en cuando lloraba y, dejaba de hacerlo cuando ella lo tomaba en brazos.

La mujer, de 20 años de edad, relató que el clima de su lugar de origen es muy distinto al de La Costa -es templado, no hace calordijo que su esposo le contaba sobre el trabajo, pero nada de la situación del calor. La expresión facial fue elocuente cuando se le pidió que opinara sobre el calor sonorense. El desagrado que implica vivir en este clima no dejó dudas sobre su experiencia en la región.

Otra mujer de Tlapa, Guerrero, de 30 años, y que ya había estado en La Costa, relató que el clima de su lugar de origen es caluroso pero sin alcanzar la intensidad del de Sonora; allá es caluroso y húmedo. Antes de venir por primera vez no contaba con información sobre el tema, su única referencia era que se ganaba mejor. 
Un informante de Huixtla, Chiapas, comentó que sí sabía del grado de calor de Sonora, no obstante, el afán de trabajar lo hizo desatender tal situación. Antes de llegar al estado, a él y a su esposa les comentaron que el clima era extremo, "cuando hacía calor, era mucho, y cuando hacía frío, era mucho frío". En su pueblo hace calor durante todo el año, pero es distinto al de La Costa: más húmedo y sudan más; gracias a la vegetación, a la sombras que proporcionan los árboles, el viento es más fresco y, por ende, las habitaciones también. En el PMA experimentan más molestias pues casi no hay viento, y cuando lo hay es caliente y levanta estelas de polvo por las calles sin pavimento. A ello se le agrega que el techo de la habitación es de lámina galvanizada, material que guarda el calor.

Para los/as migrantes, cuando salían de su tierra, la información respecto al clima pasaba a segundo término, pues la prioridad era, y es, ganar lo más posible. A diferencia de los varones, las mujeres estaban más desilusionadas por las condiciones climáticas y laborales; indicaron que las altas temperaturas representan un desafío importante para el trabajo en el lugar de residencia temporal. Un varón de Puebla, de 33 años, manifestó su contrariedad cuando se enteró de la temperatura de Sonora, lo que le platicaron antes y lo que supo cuando llegó al estado; ante la pregunta de ¿qué escuchabas de acá de Sonora?, y contestó:

pues, que era un lugar muy bonito, que se siente calor, pero pos no a temperaturas muy altas a como estamos acostumbrados, en Puebla lo muy alto pos eran que 38,37 , y aquí me hablan que de 50 , de 49 , como que sí da miedo ¿no? porque ya son temperaturas muy altas más que nada para nosotros que no estamos acostumbrados a este clima (PMA, 6 de mayo de 2014).

Tener noticias más cercanas le provocó miedo, ya que su parámetro era de $37^{\circ} \mathrm{C}$. Al salir de Puebla sabía que el verano era caluroso, pero lo que supo al estar en La Costa le generó temor, más de $45^{\circ} \mathrm{C}$. En este contexto surgen los dilemas o reconsideraciones respecto al tiempo de permanencia en La Costa y, en general, en Sonora. Si bien en ciertos momentos el empleo-ingreso juega un papel decisivo, se plantean la disyuntiva de la salida del lugar ante factores que menguan la salud de algunos integrantes de la familia. 
Los varones de Huixtla y Puebla laboraban permanentemente en una actividad remunerada. Las dos mujeres, de Tlapa y Tuxtla Gutiérrez, dejaban de trabajar por enfermedad de sus hijos o necesidad de lavar la ropa acumulada. La experiencia con el calor es distinta, mientras que los varones le hacen frente durante la jornada en el surco, ellas lo enfrentan de manera intermitente, tanto en el surco como en el hogar. Las esposas de los informantes de Huixtla y Puebla permanecían más tiempo en sus casas, en estos casos la normativa masculina del trabajo se expresaba con mayor nitidez. De este modo, el deber del trabajo para los varones a veces se atenúa.

\section{Al calor de la masculinidad: entre cuero de oso y el padecimiento agudo}

Carolina Rosas (2008) señala que la migración de los varones de Veracruz en cierta forma se presenta como prueba de masculinidad, como una manera de demostrar valentía y enfrentar los peligros que les depara el desplazamiento geoespacial. Aunque las mujeres también asumen la proveeduría familiar, o enfrentan dificultades en la misma magnitud que los varones durante el proceso migratorio, el peso cultural es distinto.

Durante los recorridos de campo se recopilaron relatos de migrantes respecto a la experiencia con el calor desde que arribaron a Sonora, hace más de treinta años. En una entrevista informal en abril, un mixteco de alrededor de 60 años relató que cuando tenía 19 laboraba en la pizca de algodón -en un poblado del sur del estado- y al mediodía, a la hora de la comida, sus compañeros optaron por suspender las labores, no obstante él prefirió seguir trabajando para ganar más. Recordó, con un dejo de risa, que sufrió malestares por los efectos de la exposición al sol, lo que le provocó que se desmayara por algunos minutos, al regresar a sus labores un compañero lo encontró inconsciente en el suelo. Admitió que su desmayo no sólo se debió a la falta de experiencia (y pericia), sino a que su condición de joven, de creerse inmune, contribuyó al desenlace.

En la actualidad, este informante ya desarrolló resistencia física que, junto con la precaución de no exponerse demasiado a los rayos 
del sol, le ha permitido sobrellevar las inclemencias del tiempo tanto en el trabajo agrícola como en el de la construcción en el PMA. Las dificultades aumentan para algunos varones con poca o nula experiencia previa con respecto al clima de Sonora. Además, para quienes tienen molestias, con episodios agudos o crónicos de enfermedad, las temperaturas altas tienden a agravarlas. Las normativas masculinas, relacionadas con la masculinidad tradicional, llegan a presionarlos para que, a pesar de todo, laboren y se expongan a las severidades climáticas.

La idea de aguantar el clima extremo no nace de la experiencia previa, más bien tiene un origen cultural. La intersección con la etapa de vida muestra una masculinidad llena de desafíos y retos, que hacen vivenciar el padecimiento de manera diferencial con respecto a las migrantes entrevistadas.

Si bien se trata de varones y mujeres que en general buscan conseguir el ideal de bienestar familiar a toda costa, hay diferencias en determinadas situaciones y etapas biográficas. Casi todas las entrevistadas habían llegado por primera vez a Sonora; la mayoría de los varones ya tenían varias temporadas insertados en una dinámica migratoria pendular. En este sentido, las quejas sobre el clima se yuxtaponen con las dificultades en la salud de sus hijos o la propia. Las mujeres con experiencia previa no dejaban de quejarse de las inclemencias del tiempo. El testimonio de algunos varones fue elocuente:

[...] me gusta aquí el clima, aquí no es muy [...] 'ta fresco, no es muy caliente, porque yo he estado, he trabajado en la sandía cuando está caliente pero como ya estoy impuesto al calor más fuerte, entonces es que no me hace daño, ya estoy impuesto (PMA, 7 de mayo de 2014).

La alusión del informante de 40 años, originario de Jalisco, respecto a que está impuesto se debe a su trabajo anterior en Estados Unidos; según narra, en los lugares en los que vivió el calor es más "alto" que en La Costa. El parámetro que usa para afirmar esto es su percepción subjetiva, el contraste entre el "antes" y el "ahora” en términos temporales lo circunscribe a la experiencia del cuerpo. Es posible que junto a dicha percepción, de que el calor no representa 
un problema para su salud, esté también la idea cultural interiorizada de la hombría, de que el ser "hombre" conlleva necesariamente una dosis fuerte de valentía. Aunado a lo anterior, la experiencia adversa de Ismael en Estados Unidos hizo que relativizara el malestar por el calor, en especial por su trabajo en Arizona. Según él, le gusta el clima pues considera que no es muy caliente.

Además de los eventos de gravedad de dos entrevistados con enfermedades agudas, los varones no expresaron contrariedad por el clima, al grado de reconocer que fuera un problema. Una mujer narró que haber trabajado en Tabasco le ayudó a enfrentar bien el calor de Sonora. El resto de las entrevistadas manifestaron haber sufrido dolores de cabeza y mareos debido a las altas temperaturas.

\section{Figura 2}

¿Consideras el clima de Sonora un problema para tu salud?

\begin{tabular}{|c|c|c|}
\hline Informante & Respuesta & Experiencia con clima extremo \\
\hline Mujer & No & Sí \\
\hline Varón & Sí & No \\
\hline Mujer & No & Sí \\
\hline Varón & No & No \\
\hline Mujer & Sí & No \\
\hline Varón & Relativo & No \\
\hline Mujer & Sí & Sí \\
\hline Mujer & Sí & No \\
\hline Mujer & Sí & Sí \\
\hline Varón & Poco & Sí \\
\hline Varón & No & Sí \\
\hline Varón & No & Sí \\
\hline Varón & No & No \\
\hline Varón & Sí & Sí \\
\hline Varón & Sí & No \\
\hline Mujer & Sí & No \\
\hline Varón & No mucho & Sí \\
\hline Varón & No & Sí \\
\hline Varón & No & \\
\hline
\end{tabular}

Fuente: elaboración propia. 
De las 19 entrevistas grabadas -7 mujeres y 12 varones-, 8 contestaron contundentemente que el clima no era problema para su salud, y las respuestas de tres fueron: "no mucho", "poco", “depende”. De los 11 que respondieron de manera tajante y que modularon su respuesta, dos eran mujeres, una tenía experiencia previa y la otra no. De los varones que contestaron que no era problema para su salud, seis ya habían trabajado en algún lugar con clima caluroso, según su propia referencia respecto a lo que se considera como "caluroso". Y dos de los tres, que sí pensaron que era un problema, tuvieron molestias agudas, que llegaron a ser incapacitantes.

Javier, de 29 años, con experiencia de migración pendular e internacional, es el prototipo, por lo menos en el discurso que expresa, del "hombre" inquebrantable ante la enfermedad; lo único que le aquejaba era el cansancio cuando salía del trabajo y llegaba a la cuartería, "pero es normal", dijo. El calor "no nos hace nada", por ende, sin ambivalencias y rodeos apuntó que "el clima no nos preocupa a nosotros, nosotros como cuero de oso". Javier vivió episodios traumáticos por accidentes en Estados Unidos relacionados con problemas de alcohol. Podría parecer que su percepción del riesgo estaba en sintonía con la creencia de que era invulnerable al daño, pero no es así. Una manera indirecta de matizar su postura inquebrantable ante las molestias es reconocer que:

$[\ldots]$ para cualquier gente que viene por primera vez y no ha salido, no conoce el clima, tal vez eso puede ser peligroso, porque sí se desmayó un amigo, del calor (PMA, 9 de mayo de 2014).

Ante el matiz manifestado por el informante, se le lanzó de nuevo una pregunta directa: entonces, ¿el clima no es problema para ti?, y contestó sin vacilar: no "ni tantito". Intentó vincular lo vivido en su trabajo en Estados Unidos, con una especie de aprendizaje socioambiental en el cual "el cuerpo se acostumbra" a un clima extremo, ya que lo vivido en los campos de Florida, EE UU, resultó más adverso que en Sonora. Es semejante a lo expresado por Ismael, para quien acostumbrarse es vital para tener éxito en las faenas del campo. Subyace en estos relatos, y en la construcción de la percepción del riesgo ante las temperaturas elevadas, un entrecruzamiento de la idea de la ex- 
periencia previa, y la fortaleza para asimilar los primeros efectos en la salud.

Las identidades están en interacción y trasformación permanente, y las masculinas se ven expuestas en el proceso migratorio, lo que implica, sobre todo, estar a merced de peligros socioambientales. Javier es una muestra de cómo se entrecruzan los procesos migratorios internacionales e internos en los que se va forjando una idea de sí mismo en el sentido sociológico, en la cual la metáfora del cuero de oso refleja una posición frente al aguante al clima, pero junto a un cambio sobre su definición del ser hombre. Cuando Javier vive en el PMA acepta que su esposa le ayude, y él participa en las tareas domésticas.

Don Lencho es de Nayarit, tiene más de 50 años, y aseveró que evitaba quedarse en el PMA después de junio; no consideraba las altas temperaturas un problema para su salud. Cuando se le interrogó respecto a lo que le contaron sobre Sonora antes de llegar, señaló que el "calor, mucho calor, pero aquí nomás estamos hasta julio, luego nos vamos, porque aquí está el calor” (PMA, 2 de mayo de 2014). La sorpresa fue que a pesar de considerar al clima como un problema, pues se regresan antes de una fecha que juzga complicada para seguir trabajando, respondió lo siguiente a la pregunta: ¿considera usted el clima de Sonora un problema para su salud?

pues no, suda uno mucho pero pues no, riesgo no, pero tampoco nos quedamos $[\ldots]$ en mayo está trabajable porque todavía no hace mucho calor, está más o menos, ya a fines de junio está cabrón [...] (PMA, 2 de mayo de 2014).

Una explicación alternativa ante esta contradicción es que la percepción del riesgo la construye con un barómetro que mide su tolerancia a un malestar demasiado alto, pues es capaz de enfrentar "el calor de mayo", y sufrir de sus estragos y no considerarlo un problema. El límite es salirse de este rango de tolerancia, es un poco la idea del umbral del dolor aludido en la literatura antropológica. Sin embargo, media un proceso intersubjetivo para establecer el parámetro alto, que se origina en la cuna de su socialización; hay una estructura normativa que lo alimenta.

Don Lencho no catalogó al calor como un problema para su salud, aunque después reconoció haber sentido "molestias". Es decir, admi- 
tió un umbral que marca hasta dónde puede enfrentar, vivir con el calor: es hasta finales de junio, porque para él es trabajable.

Después de varias experiencias migratorias, don Lencho ha sabido sortear el clima, principalmente el calor y, pese a que dijo que no representaba un problema, ante la pregunta de si había sentido molestias, señaló contundente: "Nosotros no". Más adelante reconoció que tomaba sueros orales cuando sentía caliente el cuerpo, y que:

[...] [toma suero] en el trabajo, allá sí porque anda uno en chinga pues a vuelta y vuelta y siente uno el cuerpo como que empieza a temblar y ahí con unos dos tres traguitos de suero, se acomoda uno y síguele $[\ldots]$ (PMA, 2 de mayo de 2014).

La relación trabajo-calor-masculinidad será importante para los varones jornaleros migrantes. Aunque para las mujeres el trabajo es relevante, para los jornaleros migrantes varones la relación trabajo-calor-masculinidad constituye un eje muy importante, porque su significado parte de la idea que tienen sobre sí mismos, como "hombres". Ante la pregunta sobre qué dificultades había sorteado en su estancia temporal, don Lencho dijo: "Se me atora el carro para la renta pero ahí vamos a salir"; un eje modular de la identidad masculina representa la idea de proveeduría. A pesar de que su esposa "le ayuda" con los gastos, personificó el problema en sí mismo cuando terminó el relato anterior con la frase: "Se acomoda uno y síguele". Manejar las dificultades tanto del cuerpo como de la subsistencia familiar se sintoniza con la idea de la obligación social masculina de proveeduría.

Javier contó que en su pueblo es obligación de los "hombres" ver por sus familias, es impensable que su pareja le ayude. No obstante, este imperativo se matiza en un proceso migratorio. Cuando emigran los dos, por necesidad práctica las mujeres se incorporan a la actividad productiva formal, pero siempre en el entendido de que se trata de una situación temporal y, en algunos casos, para ellas no significa una mejoría, pues cumplen también con la expectativa social de lavar, limpiar y hacer la comida, una vez terminada su rutina laboral. Pese a la diferencia de edad, don Lecho y Javier son una muestra de formas de masculinidad con rasgos de la normatividad de género compartida. Ellos ayudan a sus parejas en el lugar de destino, no ven el calor 
como problema, pero en sus lugares de origen aplican la normativa tradicional de la división sexual del trabajo.

Durante las entrevistas, tanto los varones como las mujeres se refirieron a su experiencia con el clima en alusión permanente al cuerpo; que el cuerpo empiece a temblar es señal inequívoca de los límites físicos. La noción de prevención se limita a tomar mucha agua y suero, como última medida, pues señalaron que a ninguno le gustaba el sabor.

Sócrates, un migrante amuzgo de 34 años, de Oaxaca, tenía molestias agudas, y se le agravaban en tiempo de calor. Ante la pregunta respecto a lo que siente con las temperaturas elevadas, dijo:

[...] como bien cansado mi cuerpo, muy cansado el cuerpo, no tengo fuerza porque pinchi calorón que hace muy fuerte, tomo agua de suero se calma, medio fresco quedo, poquito ya (PMA, 8 de mayo).

Sócrates le atribuyó su cuerpo cansado al entorno, es decir, al clima, y el líquido electrolítico llamado suero es un aliciente para ello. Si el trabajo agrícola en el surco suele ser rudo y agobiante, agregar calor natural excesivo produce cuerpos cansados. Él mismo se apega a un tipo de masculinidad que enfatiza el aguante físico y superioridad frente a otros. Pero cuando reconoce sus limitaciones físicas implica una apertura emocional, es decir, una sensación de vulnerabilidad. Esto se acentúa más tras sufrir un asalto durante su experiencia migratoria, lo cual lo impulsó a un aislamiento social.

En cuanto al padecimiento, Sócrates dijo que debía tomar "pastillas", pero no supo decir de cuáles, con las que mitigaba la hemorragia nasal y el dolor de cabeza. A diferencia de las entrevistadas, que expresaron molestias por el calor, a la pregunta de ¿cómo es un día cuando estás trabajando así? Sócrates contestó:

pues muy mal, como yo pues me da vergüenza decir, aquellos de los campos preguntan si alguien está enfermo digan, hay pastillas, como yo me da vergüenza, me quedo calladito, nadie sabe, nomás yo sé lo que siento yo pues muy mal (PMA, 8 de mayo de 2014).

La respuesta causó sorpresa, y de inmediato se le preguntó por qué razón le daba vergüenza. A lo que contestó que "[...] porque hay mucha 
gente pues, dicen 'no ese wey nomás hace nomás acá, no está enfermo', y eso pues pensaba yo me da vergüenza yo, así nomás”.

Hay varias interpretaciones de los dichos de Sócrates, en primer lugar la idea de que puedan pensar que está fingiendo para no laborar y así cobrar, lo vuelve blanco de un estigma, lo que se resume en la expresión ese wey. Si una trabajadora estuviera en la misma situación, es probable que no sintiera temor de ser etiquetada como ese wey. Con una dinámica de género se puede explicar cómo funciona la generación social de la vergüenza en un indígena migrante, y en particular en un hombre que se jacte de serlo. En este contexto masculinizado, es complicado pensar que a una mujer se le señale como "esa wey", cuando quepa la sospecha de que finge una molestia para no laborar.

María, una migrante mestiza de 19 años, también dijo que el calor era insoportable, y que tuvo mareos después de trabajar más de las ocho horas. Las prácticas preventivas, cuando varones y mujeres reconocían los malestares causados por el calor, se limitaban a beber agua, y a descansar cuando se sentían mareadas/os. Un informante en un albergue de Agua Prieta, con antecedentes migratorios en La Costa, dijo que era común preparar una bebida para aguantar las jornadas fatigosas de verano. A una botella de agua le agregaban harina de maíz (conocida como Maseca), y la tomaban durante el día; los menos preparaban los sobres de vida suero oral y, en algunos casos, las autoridades de los campos se los ofrecían.

Al preguntar quiénes se cuidaban más de las temperaturas altas, una respuesta común fue que las mujeres. Por ejemplo, a pesar que el sabor del suero les resultaba desagradable, ellas lo utilizaban mayormente. También, muchas, como María, se cubrían el rostro con pañuelos para protegerse del sol, y aunque también los varones lo hacían, varios/as informantes coincidieron en que las mujeres los usaban con más regularidad.

Es complicado pensar en cuidarse de las temperaturas elevadas, cuando es improrrogable obtener el salario diario en cualquier condición. Aun así, hubo personas que tuvieron la determinación de cesar las labores de manera unilateral cuando sentían demasiadas adversidades, principalmente climáticas. Las normativas masculinas, ya sea de proveeduría o de valentía, pasan a segundo término cuando se traspasan los umbrales de tolerancia (construidos de manera inter- 
subjetiva), sobre todo al conjugarse con una condición previa de enfermedad o lesión. Un ejemplo dramático de esto es el caso de Raúl, originario de Iguala, Guerrero, quien, a pesar de que tenía un tumor cerebral, manifestaba su intención de trabajar para velar por su familia.

En varios de los casos abordados, la noción del cuerpo era central, tanto para la experiencia ante las altas temperaturas como para la definición de la masculinidad, porque era el medio por el cual se vivían o sentían las lesiones, las molestias o las enfermedades. La vivencia sobre el calor u otro evento no se logra en el vacío, sino por medio de relaciones sociales, y en este caso, de las de género. Algunas de las referencias de los entrevistados respecto al calor se pueden sintetizar con las frases: "El cuerpo empieza a temblar", "el cuerpo lo siente", "el cuerpo te avisa". De tal manera que, si se retoma a Connell, la posición de género tiene un efecto en las prácticas, y la experiencia corporal retroalimenta la personalidad y la cultura $(1997,35)$.

\section{Conclusiones}

Hay varones que pueden responder de la misma forma a las exigencias del trabajo agrícola, y con ello a los peligros medioambientales y, a la vez, reproducir una matriz cultural que promueve su preeminencia frente a las mujeres. También es posible que existan varias expresiones de cómo los varones se cuidan del calor, la enfermedad o de la posibilidad de un accidente. En este sentido, si bien los jornaleros agrícolas estudiados produjeron discursos y prácticas que reivindicaron los valores como la fortaleza y la invulnerabilidad ante el peligro, en la lógica de las necesidades materiales y sociales, hubo quienes tomaron suero, se quejaron del dolor, no laboraron cuando se sintieron enfermos. Las normativas masculinas influyen en la percepción sobre el riesgo ante las temperaturas elevadas, pero en ciertas circunstancias. Dichas normativas no son monolíticas, pues se interpretan a la luz de los dilemas o de las necesidades que surgen de la experiencia de los varones. Las identidades masculinas esbozadas representan sólo algunas de las expresiones de las masculinidades múltiples, que se forjan en la migración y el trabajo agrícola; la experiencia con el clima es una vía, de otras posibles, por la que se pueden explorar las 
respuestas ante un medio adverso por parte de los/as jornaleros/as agrícolas del noroeste mexicano.

Por otro lado, el proceso migratorio se relaciona con la reproducción de las dinámicas de desigualdad social entre varones y mujeres. Dichas diferencias también repercuten en ciertas circunstancias microsociales de cara al clima extremo. Las prácticas pueden coincidir, tanto las preventivas como las osadas, no obstante, el hecho de que las entrevistadas hablaran de sus malestares y del rechazo de sus parejas al llamarlas enfermizas, muestra un proceso estigmatizador, lo cual también refleja una desvalorización.

En los migrantes, el imperativo de la proveeduría se asocia con los comportamientos, cuando se experimentan molestias por el calor. Además, con el termómetro cultural de la vergüenza, pueden ser considerados como tramposos o flojos, y con ello hacer mella en la autodefinición del ser hombre.

El contraste entre el clima de sus pueblos/ciudades de origen se resuelve con la normalización de la situación con la frase "ya estoy impuesto al clima de aquí", o se resignifica el daño potencial al no considerarlo un problema para la salud. Quienes más reconocieron molestias y el desagrado por las altas temperaturas fueron las mujeres; en el caso de padecimientos graves, los varones señalaron sus malestares pero siempre en la lógica de salvaguardar su hombría. El cuerpo, tanto en varones como en mujeres, es el depositario de los efectos del calor. Para los/as jornaleros/as agrícolas la experiencia ante el clima extremo está en función de sus antecedentes migratorios en Sonora. Otro factor significativo es la condición laboral de los campos agrícolas y la sociosanitaria de la localidad de residencia. Es importante no perder de vista dichos elementos para el análisis sobre la construcción social del riesgo en el grupo social de referencia.

Por último, hay que apuntar que algunas formas de expresar la masculinidad ocurren en la lógica de una marginación social, en términos de la etnia y la clase. Por definición, los/as jornaleros/as se ubican socialmente en una estructura que provee poca seguridad social, donde los satisfactores materiales son deficientes y que viven un proceso de exclusión, junto con el cual existen jerarquías internas que simbolizan formas de masculinidades que se subordinan, en este caso, la indígena. Entonces, algunos jornaleros experimentan una 
marginación o explotación triple, lo cual los vuelve más vulnerables a los daños. También muchas jornaleras viven dichas adversidades y, a la vez, guardan similitudes y diferencias con sus compañeros.

\section{Bibliografía}

Amuchástegui, Ana e Ivonne Szasz (coordinadoras). 2007. Sucede que me canso de ser hombre... Relatos y reflexiones sobre los hombres y masculinidades en México. México: El Colegio de México (COLMEX).

Calvario, Eduardo. 2014. Género y masculinidad: juegos de poder y configuración del peligro en el poblado Miguel Alemán, Sonora. Tesis de doctorado en ciencias sociales, COLMEX.

Calvario, Eduardo. 2003. Masculinidad, padecimientos y riesgo laboral en jornaleros agrícolas del poblado Miguel Alemán, Sonora. Tesis de maestría en ciencias sociales, COLSON.

Calvario, Eduardo y Gilda Salazar. 2012. Pero sigo siendo el rey. Masculinidad y malestares emocionales en un contexto de migración en la Costa de Hermosillo. En La salud y la migración en México, coordinado por Alfonso Mejía, Dominga Nazar-Beutelspacher y Benito Salvaterra, 161-179. Toluca, Gobierno del Estado de México, Universidad Autónoma del Estado de México y El Colegio de la Frontera Sur (ECOSUR).

Careaga, Gloria y Salvador Cruz Sierra (coordinadores). 2006. Debates sobre masculinidades. Poder, desarrollo, políticas públicas y ciudadanía. México: Programa Universitario de Estudios de Género (PUEG)-Universidad Nacional Autónoma de México (UNAM).

Carton de Grammont, Hubert. 2007. Las empresas, el empleo y la productividad del trabajo en la horticultura de exportación. En Los jornaleros agrícolas, invisibles productores de riqueza. Nuevos procesos migratorios en el noroeste de México, coordinado por María I. Ortega, Alejandro Casta- 
ñeda y José L. Sariego, 15-46. México: Centro de Investigación en Alimentación y Desarrollo (CIAD), Fundación Ford, Plaza y Valdés.

Cedillo, Leonor y Frineé Cano (coordinadoras). 2012. Género, ambiente y contaminación por sustancias químicas. México: Secretaría de Medio Ambiente y Recursos Naturales (SEMARNAT).

Centro de Derechos Humanos de la Montaña Tlachinollan. 2012. Migrantes somos y en el camino andamos. Talpa: Informe del Centro de Derechos Humanos de la Montaña Tlachinollan.

Centro del Agua del Trópico Húmedo para América Latina y El Caribe, Programa de Naciones Unidas para el Desarrollo. 2008. Fomento de las capacidades para la etapa II de adaptación al cambio climático en Centroamérica, México y Cuba. Panamá: Centro del Agua del Trópico Húmedo para América Latina y el Caribe, Programa de las Naciones Unidas para el Desarrollo, Global Environment Facility.

CIDH. 2013. Derechos humanos de los migrantes y otras personas en el contexto de la movilidad humana en México. Washington: CIDH, Organización de Estados Americanos.

CONAGUA. 2014. Resumen datos climatológicos, 1925-2011. Por Organismo de Cuenca Noroeste: Organismo de Cuenca Noroeste: CONAGUA.

Conde, Ana Cecilia y Carlos Gay (coordinadores). 2008. Guía para la generación de escenarios de cambio climáticos a escala regional. México: UNAM.

Connell, Robert. 1997. La organización social de la masculinidad. En Masculinidades. Poder y crisis, editado por Teresa Valdés y José Olavarría, 31-48. Santiago: Isis Internacional.

De Keijzer, Benno. 1998. El varón como factor de riesgo: masculinidad, salud mental y salud reproductiva. En Género y salud en el sureste de México, coordinado por Elsa Tuñón, 199-219. México: ECOSUR. 
Díaz, Rolando, Lucía Castro y Patricia Aranda. 2014. Mortalidad por calor natural excesivo en el noroeste de México: condiciones sociales asociados a esta causa de muerte. Frontera Norte XXVI (52):155-177.

Fuller, Norma. 1998. La constitución social de la identidad de género entre varones urbanos de Perú. En Masculinidades y equidad de género en América Latina, editado por Teresa Valdés y José Olavarría, 56-68. Santiago: Facultad Latinoamericana de Ciencias Sociales-Chile, y Fondo de Población de las Naciones Unidas.

Hawkesworth, Mary. 1996. Confundir el género. Debates Feministas 10 (20): 3-54.

Hernández, Oscar, Arcadio García y Koryna Contreras (coordinadores). 2011. Masculinidades en el México contemporáneo. México: Universidad Autónoma de Tamaulipas (UAT), Plaza y Valdés.

Izcara, Simón Pedro. 2013. La etiología de la migración permanente en la zona citrícola de Tamaulipas. México: Porrúa, UAT.

Jáuregui, Ernesto, Adalberto Tejeda, Elda Luyando, Mario Casasola y Guillermo García. 2008. Asentamientos humanos: bioclima, isla de calor y consumo eléctrico. México. SEMARNAT, Instituto Nacional de Ecología, UNAM.

Lamas, Marta (compiladora). 1996. El género: la construcción cultural de la diferencia sexual. México: PUEG-UNAM, Miguel Ángel Porrúa.

Lara, Sara. 1992. La flexibilidad del mercado de trabajo rural: una propuesta que involucra a las mujeres. Revista Mexicana de Sociología LIV (1): 29-48.

Moreno, Ana. 2010. El cambio climático y la salud humana. En México ante el cambio climático. Evidencias, impactos, vulnerabilidad y adaptación, compilado por María José Cárdenas, 24-25. México: Greenpeace México. 
Núñez, Guillermo. 2013. Hombres sonorenses: un estudio de género de tres generaciones. México: Universidad de Sonora y Pearson (Educación de México).

Núñez, Guillermo. 2001. Reconociendo los placeres, deconstruyendo las identidades. Antropología, patriarcado y homoerotismo. Desacatos (6): 18-36.

Ortega, Isabel, Patricia Aranda, Cecilia Rosales y Jill Guernsey. 2008. La salud de los jornaleros migrantes y un modelo de la responsabilidad social de las empresas agrícolas, Informe final. Universidad de Arizona, CIAD, COLSON.

Ortega, Isabel y Alejandro Castañeda. 2007. Los jornaleros agrícolas en Sonora: condiciones de nutrición y salud. En Los jornaleros agrícolas, invisibles productores de riqueza. Nuevos procesos migratorios en el noroeste de México coordinado por Isabel Ortega, Alejandro Castañeda y Juan L. Sariego, 145-158. México: CiAD, Fundación Ford, Plaza y Valdés.

Ortega, Isabel, Alejandro Castañeda y Juan L. Sariego (coordinadores). 2007. Los jornaleros agrícolas, invisibles productores de riqueza. Nuevos procesos migratorios en el noroeste de México. México: CIAD, Fundación Ford, Plaza y Valdés.

Piñeiro Sande, N., J. L. Melgar Martínez, E. lemparte Pardavila y J. C. Rodríguez García. 2004. Golpe de calor. Emergencias XVI (3): 116125.

Ramírez, Juan Carlos y José Carlos Cervantes (coordinadores). 2013. Los hombres en México: veredas recorridas y por andar. Una mirada a los estudios de género de los hombres, las masculinidades. México: Centro Universitario de Ciencias Económico Administrativas de la Universidad de Guadalajara, Academia Mexicana de Estudios de Género de los Hombres.

Rivas, Eloy. 2005. ¿El varón como factor de riesgo? Masculinidad y mortalidad por accidentes y otras causas violentas en la sierra de Sonora. Estudios Sociales XIII (26): 27-66. 
Rosas, Carolina. 2008. Varones al son de la migración. Migración internacional y masculinidades deVeracruz a Chicago. México: COLMEX.

Saldaña, Abril. 2015. Ecofeminismo, mujeres y desarrollo sustentable: el caso de la Sierra de Santa Rosa en Guanajuato. región y sociedad XXVII (62): 63-96.

Saldaña, Adriana. 2014. Intermediarios laborales en Morelos: abasto de jornaleros agrícolas en el centro y el noroeste de México. Estudios Sociales XXII (43): 139-158.

Sariego, Juan L. y Alejandro Castañeda. 2007. Los jornaleros agrícolas de Sonora: recuento de una experiencia de investigación. En Los jornaleros agrícolas, invisibles productores de riqueza. Nuevos procesos migratorios en el noroeste de México coordinado por Isabel Ortega, Alejandro Castañeda y Juan L. Sariego, 119-144. México: CIAD, Fundación Ford, Plaza y Valdés.

Scott, Joan. 1996. El género, una categoría útil para el análisis histórico. En El género: la construcción cultural de la diferencia sexual, compilado por Marta Lamas, 265-302. México: PUEG-UNAM, Miguel Ángel Porrúa.

Seefoó, José Luis. 2005. La calidad es nuestra, la intoxicación... ide usted! Atribución de la responsabilidad en las intoxicaciones por plaguicidas agrícolas, Zamora, Michoacán, 1997-2000. Zamora: El Colegio de Michoacán.

SEDESOL. 2011. Pobreza, migración y capacidades básicas en la población jornalera agrícola en México. Resultados de la encuesta nacional de jornaleros agrícolas 2009. Gobierno de la república: SEDESOL.

Tuñón Pablos, Esperanza. 2003. Género y medio ambiente. Ciudad de México: Plaza y Valdés, ECOSUR, SEMARNAT.

Ulloa, Astrid. 2011. Construcciones culturales sobre el clima. En Perspectivas culturales del clima, editado por Astrid Ulloa, 33-54. Bogotá: Universidad Nacional de Colombia e Instituto Latinoamericano para una Sociedad y un Derecho Alternativo. 
Verbrugge, Louis. 1985. Gender and health: an update on hypotheses and evidence. Journal of Health and Social Behavior (26): 156-182.

Viveros, Mara. 1997. Los estudios sobre lo masculino en América Latina. Una producción teórica emergente. Nómadas (6). http:// www.redalyc.org/articulo.oa?id=105118999005 (agosto 2015).

Waldron, Ingrid. 1995. Contributions of changing gender differences in behavior and social roles to changing gender differences in mortality. En Men's health and illness. Gender, power and the body, coordinado por Donald Sabo y David F. Gordon, 22-45. Londres: Sages Publications. 